\title{
Multicriteria decision analysis in water resources management: the malnichara channel improvement
}

\author{
${ }^{1 *}$ R. K. Chowdhury; ${ }^{2}$ R. Rahman \\ ${ }^{1}$ South Australia Center for Water Management and Reuse, School of Natural and Built Environments, University \\ of South Australia, Mawson Lakes, SA 5095, Australia \\ ${ }^{2}$ Institute of Water and Flood Management, Bangladesh University of Engineering and Technology, Dhaka-1000, \\ Bangladesh
}

Received 9 January 2008; revised 3 February 2008; accepted 28 Ferbruary 2008; available online 10 March 2008

\begin{abstract}
Multicriteria decision analysis tool is used in many water resources and environmental management projects. The Malnichara is one of the natural channels in Sylhet city (Bangladesh) responsible for storm runoff conveyance to the downstream Surma river. The channel is found to be encroached at many locations of the city and found to be very vulnerable. The authority has taken decision to improve natural channels by a traditional approach, e.g. constructing box culvert. In most cases, stakeholders' participation is ignored in such type of decision making. Hence, efforts were made to evaluate three common alternatives viz. sodding natural channel, lined natural channel and box culvert for the channel improvement. The channel is hydrologically divided into two parts: the upper portion (Choukidekhi-Kanishail) and the lower portion (Kanishail-Topoban). Both parts were separately analyzed. Small groups of stakeholders were interviewed for the selection of criteria and for the assignment of weighed factor and scores. Experts' opinions were also taken through consultation. Nine criteria from four categories such as technical, economic, environment and social aspects were selected. The relative performances of alternatives were evaluated using the weighed sum technique of multicriteria decision analysis. It was found that the sodding natural channel is the best alternative for both portions of the channel. However, the choice is very sensitive to the social criteria.
\end{abstract}

Key words: Drainage channel, urban area, alternatives, criteria, stakeholder participation

\section{INTRODUCTION}

The role of public participation in water resources and environmental project is now acknowledged. However, in many developing countries like Bangladesh, public participation during planning and decision-making process is not properly followed. As a result, stakeholders' opinions may not have had any impact on either the process or its outcome and thus dissatisfaction may arise (Marttunen and Suomalainen, 2005). In order to avoid such dissatisfactions and unsustainability of the project, stakeholders' participation must be ensured from the very beginning of the project. Nowadays, environmental awareness is increased and the number of stakeholders is more than that of a few preceding decades (Senecah, 2004). Thus, the requirements of a holistic and analytic tool for combining ecological, social and economic aspects of a project is high (Marttunen and Suomalainen, 2005). Multicriteria decision analysis (MCDA) is such a tool

*Corresponding Author Email: rezaul.chowdhury@unisa.edu.au Tel.: +618 83025 597; Fax: +618 83023379 that is now applied in water resources and environmental projects to support public participation processes in many ways (Belton and Stewart, 2002). MCDA is an approach as well as a set of techniques aiming at providing an overall ordering of alternatives from the most preferred option to the least preferred one. The options may differ based on their several objectives and no option will be obviously best in achieving all objectives. MCDA is a technique looking at complex problems characterized by any mixture of monetary and non-monetary objectives to break the problem into more manageable pieces to allow data and judgments to be brought onto the pieces. Then, it reassembles the pieces to present a whole coherent picture to decision makers (Dodgson et al, 2000). Typically, MCDA methods have been applied in supporting the choice among different alternatives (Marttunen and Suomalainen, 2005).

(i) In Bangladesh, formal public participation through the MCDA method in water resources projects is rare. 
In most cases, stakeholders' participation is ensured by the approval of public representatives, e.g. Chairman of Union Parishad, the smallest administrative unit of Bangladesh.

In Sylhet city (the north-eastern divisional city of Bangladesh), many water resources projects have been recently planned to be performed in the Sylhet City Corporation (SCC) and Local Government Engineering Department (LGED). One of such projects is to construct traditional box culvert throughout some natural drainage channels. During field survey, it was found that public participation was neglected during project planning and execution level. Attempt was taken in this study to apply the MCDA method for public participation in order to find out the best alternative for the development of the Malnichara Channel.

\section{MATERIALS AND METHODS}

Sylhet, one of the rapidly developing urban area is situated at $28.85^{\circ}$ latitude and $98.80^{\circ}$ longitude. The region is in the hilly portion of the country. The city occupies a total area of $26.5 \mathrm{sq}$. km with a population of around 0.5 million (SCC, 2005). It has been divided into 27 administrative wards. The Surma river flows divide the city into two parts and the city is developing on both sides. It is of prime importance because of its tourism, religious places, shopping and trade centers. The city has no structured sewerage and drainage systems. A total of nine natural drainage channels is responsible for draining storm water to the downstream Surma River. Malnichara channel is one of these natural channels originated from the Malnichara tea garden.

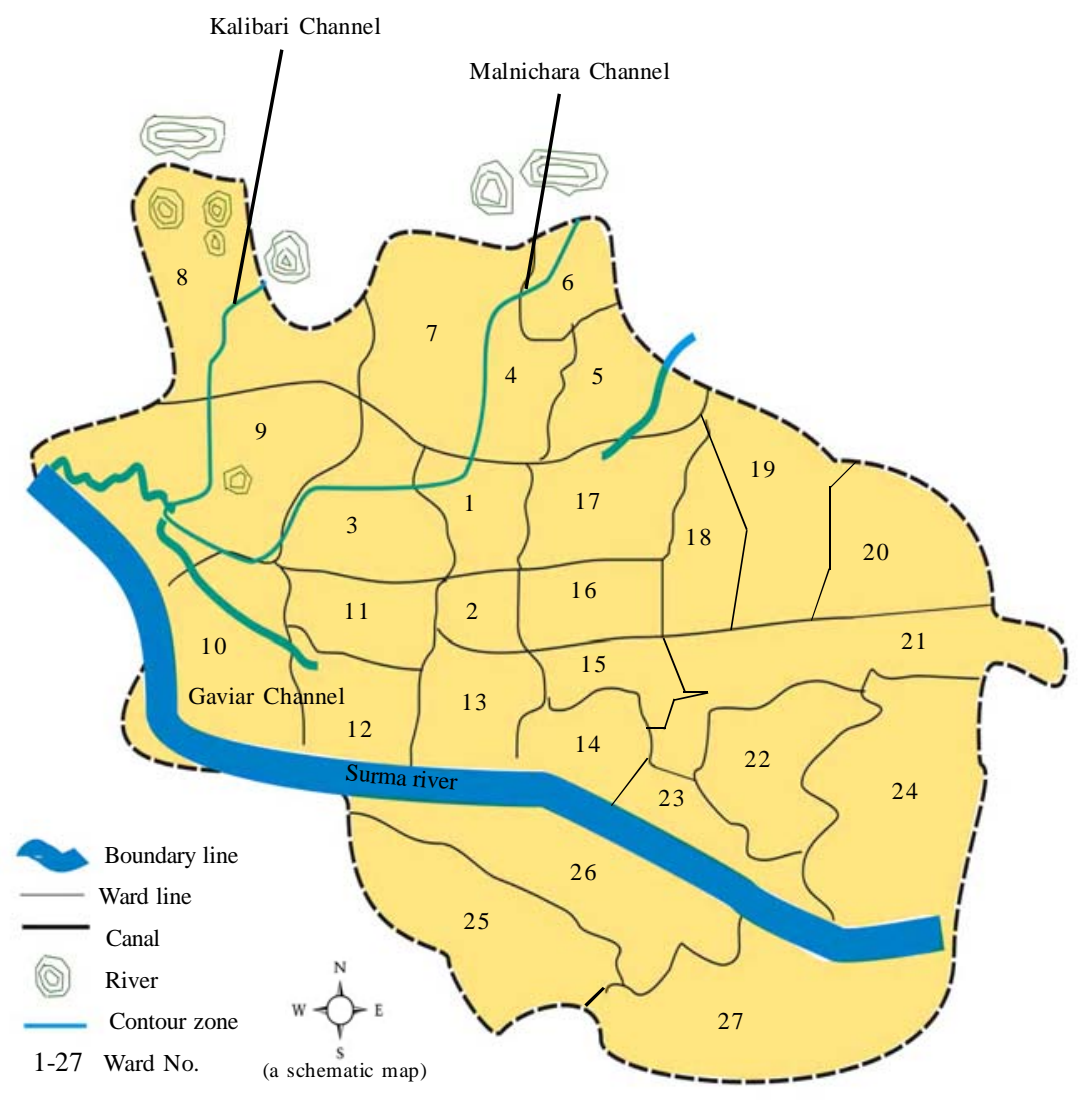

Fig. 1: Details of the studied area 
The channel enters the city at the location of Choukidekhi (ward No. 6) and runs into the city. It meets with two other small channels: the Kalibari channel and the Gaviar channel at Kanishail (ward No. 10) prior to ultimately meet with the Surma River at Topoban (ward No. 9). In the city, catchment area and the total channel length was estimated to be $10.27 \mathrm{sq}$. $\mathrm{km}$. and $9.5 \mathrm{~km}$, respectively (Chowdhury, 2005). Hydrologically, the channel length in the city can be divided into two portions: (1) Choukidekhi to Kanishail - prior to reaching other channels and (2) Kanishail to Topoban - after reaching two other channels. Estimated lengths of these two portions are $6 \mathrm{~km}$ and $3.5 \mathrm{~km}$, respectively (Chowdhury, 2005). Fig. 1 shows the details (not in scale) of the study area. During the last decade, all natural channels of Sylhet city 'including the Malnichara' are being filled up due to unplanned land development and in many locations, encroached by people. Due to unplanned urbanization and overcrowded population, the city is currently facing with many environmental consequences. Some identified problems of the Malnichara catchment area in Chowdhury (2005) are: (i) encroachment of the channel, (ii) discharge of sewage to the channel, (iii) solid waste dumping to the channel, (iv) pollutants discharge into the channel, (v) water clogging at various portions, (vi) open defecation on the channel and (vii) sediment deposition at the outfall of the channel etc.

\section{Previous studies on MCDA}

Nowadays, the MCDA method is widely used in many water resources and environmental management problems where conflict management and stakeholders' participation is of prime importance. This method is a very useful tool for practical analysis to facilitate learning process between analyst and stakeholders (Marttunen and Suomalainen, 2005). Various studies have been undertaken on the theory and practical applications of MCDA (Marttunen and Suomalainen, 2005; Belton and Stewart, 2002; Hobbs and Meier, 2000; Roy, 1996; Clemen, 1996). Some good applications on water resources and environmental management have been done by Gregory and Keeney (1994), Hostmann et al. (2005), Raju et al. (2000), Herath (2004), Lahdelma et al. (2000), Marttunen and Hämäläinen (1995), Brown (1984), Herwijnen et al. (1995), Ridgley and Rijsberman (1992), Weber and Borcherding (1993), Allett (1986), Stewart and Scott (1995), Arvai and Gregory (2003), Bella et al. (1996), Ganoulis (2003), Ning and Chang
(2002) etc. Stakeholders' involvement is one of the crucial parts of the MCDA applications. Some of the ways of arranging stakeholders' participation reported in previous studies are interviews with individual stakeholders or small groups, public consultations, workshops and decision conferences etc. (Hostmann et al., 2005). Another important task in the MCDA applications is the evaluation of alternatives. Most of the methods are based on multiple objective programing and generating alternatives by maximizing a set of objectives (Rajabi et al., 2001; Ko et al., 1994). There are some models that iteratively generate alternatives from stakeholders' preferences (Cai et al., 2004). In Bangladesh, applications of the MCDA tools on water and environmental management projects are rare. In most cases, stakeholders' involvements are conducted by Participatory Rural Appraisal (PRA) and in other cases by arranging workshops.

In this study, three alternatives of Malnichara channel improvement were selected on the basis of their frequent use in Bangladesh. The alternatives are (i) natural channel with sodding bank protection, (ii) natural channel with brick slope protection and (iii) concrete box culvert. These alternatives are included in the standard estimation and rate manual of the LGED. Hydrologically, the channel is divided into two portions, upper portion: Choukidekhi to Kanishail - prior to joining Kalibari and Gaviar channels and lower portion: Kanishail to Topoban - after reachung other two channels. Infrastructural developments along the banks and functions of the channel are different on these two portions. The upstream portion is flowing over the most densely populated part of the city whereas downstream portion is flowing over the less densely populated area. More encroachment was notified in the upstream portion than that of lower portion. Lower portion is occasionally used for irrigation, bathing and washing purposes whereas the upper portion is frequently polluted by discharging garbage and sewage. For these reasons, separate analyses have been carried out for both portions. Criterion for evaluating alternatives was selected on the basis of expected impacts of channel improvement and from expert opinions. Experts working in academic, e.g. universities, and professional organizations, e.g. SCC and LGED), were consulted for identifying these criteria. A total of nine criteria were selected and they were grouped into four categories: technical, economic, 
Multicriteria decision analysis in water resources management

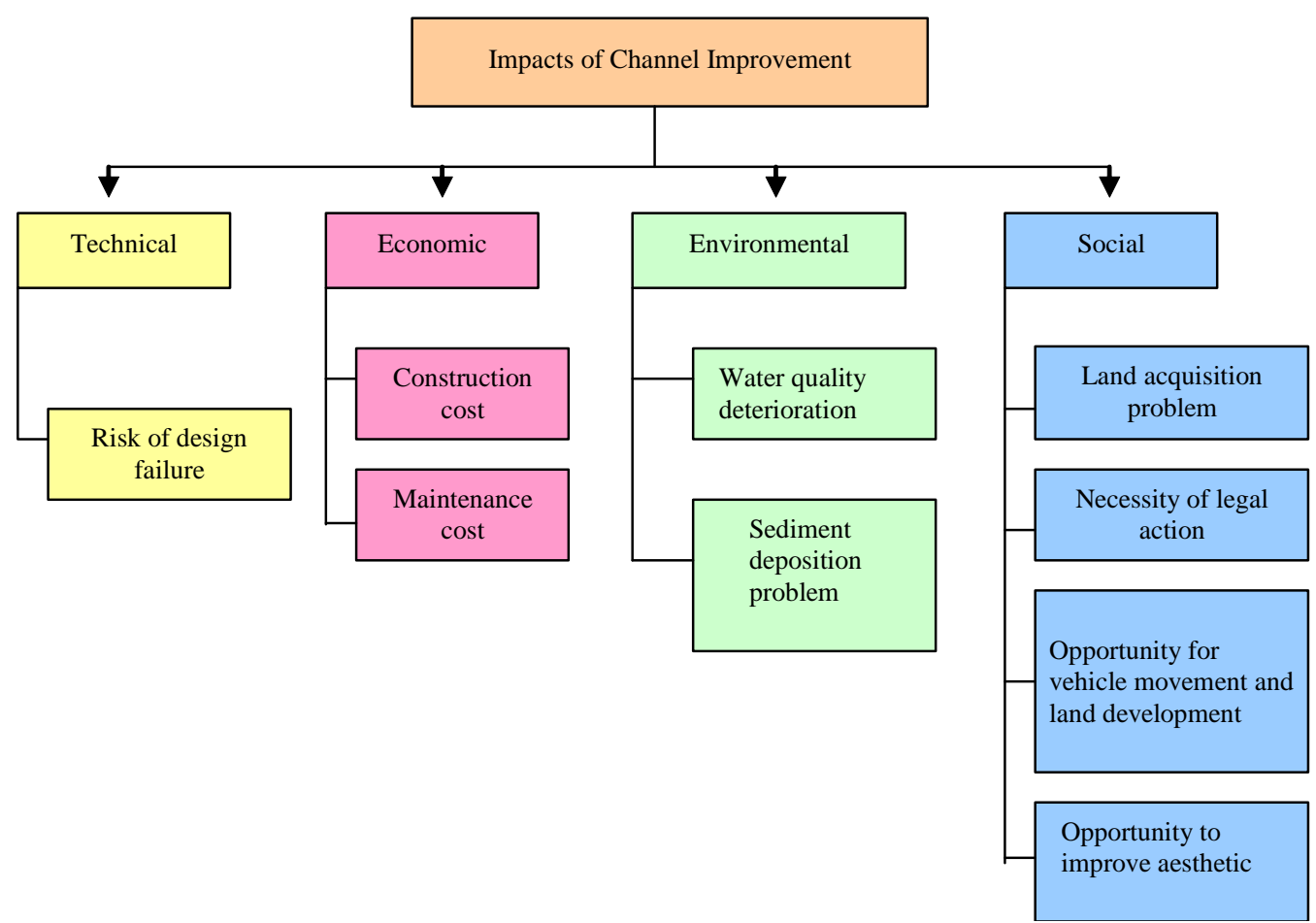

Fig. 2: Criteria used for evaluation of alternatives

environmental and social. These criteria and their groups are shown in Fig. 2.

In the MCDA methods, performance of alternatives was scored with respect to the criteria. In this study, the weighed sum method, which would be defined in the next paragraph, was used. The weighed coefficients of various criteria were assigned on the basis of public consultation and expert opinion. Small groups of stakeholders (9 people) were frequently interviewed for ranking all criteria. The participants were selected to be people who had some personal experience or an occupational view of the effects of channel improvement. Four small groups from upper channel portion and three small groups from lower channel portion were selected. Interviews and consultations were held from March to June in 2005. These interviews were generally $3 \mathrm{~h}$ long whereas consultations with experts were $2 \mathrm{~h}$ long. The interviews were made as interactive as possible. Averages of stakeholders' ratings were then cross-checked with expert opinions. Finally, based on these interviews and consultations, technical and environmental criteria were assigned with a weighed factor of 1 and the economic and social criteria were assigned with a weighed factor of 1.5 for the analysis. Alternatives were scored in cardinal scales (Tk/km, Tk/km/year) (Taka, abbreviated as Tk is the currency of Bangladesh) for economic criterion and for other criteria, ordinal scales (high/medium/low/very low) were used. There were two scenarios for assigning ordinal scores. When the ordinal scales of 'high' and 'very low' indicates the best and the worst performance, respectively, the score range was selected from 4 (high) to 1 (very low). Criteria fallen under this scenario were (i) an opportunity for vehicle movement and infrastructure development and (ii) an opportunity to improve aesthetic. Besides, when the ordinal scales of 'high' and 'very low' indicates the worst and the best performance, respectively. The selected score range was 1 (high) to 4 (very low). Criteria under this scenario were (i) risk of design failure, (ii) water quality deterioration, (iii) sediment deposition problem, (iv) land acquisition problem and (v) necessity of legal action. The scores were assigned during interviews with small groups of stakeholders and experts. Careful preparations were carried out before the interviews. General information and objectives of interviews were shared with respondents prior to provide scorecards for assigning scores. Respondents were also asked to 
give a brief argument to justify their scores. Stakeholders' scores were checked with the experts' scores. Ultimately, average scores were used. The total value of the alternative was calculated based on the weighted sum method given in the following equation (Marttunen and Suomalainen, 2005):

$V(A)=\sum_{i} w_{i} v_{i}\left(a_{i}\right)$

where, $w_{i}$ is the weight of the criterion $i, v_{i}\left(a_{i}\right)$ is the score of the alternative with respect to criterion $i$ and $V(A)$ is the value of the alternative $A$. As the scores have different unit (cardinal or ordinal), standardization is necessary to convert all scores in the same unit. Standardization means that the score of a strategy 'with respect to a criterion' is expressed as a function of the score of the other strategies. In this study, standardization was performed. The difference between the individual and the minimum score is divided by the difference between the maximum and the minimum score. The best strategy has a standardized score of one and the worst strategy has a standardized score of zero. Mathematically, the method is expressed for alternative $k$ with respect to criterion $j$ below:

$S T D_{k, j}=\left(A C T_{k, j}-W_{\text {OORST }}{ }_{k, j}\right) /\left(B E S T_{k, j}-W_{\text {OORST }}, j\right)$

where, $\mathrm{STD}_{\mathrm{k}, \mathrm{j}}$ is the standardized score, $\mathrm{ACT}_{\mathrm{k}, \mathrm{j}}$ is the actual score, WORST W $_{\mathrm{j}, \mathrm{j}}$ is the worst (minimum) score and $\mathrm{BEST}_{\mathrm{k}, \mathrm{j}}$ is the best (maximum) score. Finally, the sensitivity analysis was carried out by changing weights of different criteria so that the role of each criterion on the selection of alternatives can be understood.

\section{RESULTS AND DISCUSSION}

Scores of alternatives for both portions of the channel are shown in Table 1. It is observed that for both portions, alternatives have been assigned similar scores with respect to technical and environmental criteria and also for economic and social criteria, except for construction cost and land acquisition problem, respectively. There is no doubt that risk of design failure is high for box culvert due to less carrying capacity of it in comparison with other alternatives. Lined natural channel has more risk of bank failure and less carrying capacity than that of sodding natural one. Construction and maintenance cost of alternatives have been approximated using designed dimension of alternatives (Chowdhury, 2005) and estimation and the rate schedule of SCC. Negative sign is used for monetary scores. Proper consultation with professional engineers was made prior to assigning monetary scores. All channels have some natural purification capacity to neutralize pollutants. This purification is done by natural oxidation of channel water. In case of box culvert, the opportunity for oxidation has been reduced. This is the reason why the box culvert was assigned the worst score for water quality deterioration. Again, sodding slope has some advantages other than lined sloped channel with respect to sediment deposition and pollutant abatement. Medium score of lined channel and the best score of natural channel reasonably indicate this. As the design dimensions decrease from sodding natural channel to box culvert, land acquisition problem is reasonably low for box culvert to high one for sodding natural channel. In the upper portion of the channel, this scenario is different as many portions of the channel are encroached.

Table 1: Scores of alternatives with respect to criteria

\begin{tabular}{|c|c|c|c|c|c|c|c|}
\hline & & \multicolumn{3}{|c|}{ Choukidekhi - Kanishail } & \multicolumn{3}{|c|}{ Kanishail - Topoban } \\
\hline & \multirow[b]{2}{*}{ Criteria } & \multicolumn{6}{|c|}{ Alternatives } \\
\hline & & I & II & III & I & II & III \\
\hline Technical & Risk of design failure & $\mathrm{VL}(4)$ & $M(2)$ & $\mathrm{H}(1)$ & $\mathrm{VL}(4)$ & $M(2)$ & $\mathrm{H}(1)$ \\
\hline \multirow[t]{2}{*}{ Economic } & Construction cost $\left(\right.$ Lakh $^{*}$ Tk./km) & -22.5 & -59 & -91 & -34 & -63.5 & -107 \\
\hline & Maintenance cost (Tk./km/yr) & -6000 & -7200 & -7200 & -6000 & -7200 & -7200 \\
\hline \multirow[t]{2}{*}{ Environment } & Water quality deterioration & VL(4) & $\mathrm{M}(2)$ & $\mathrm{H}(1)$ & $\mathrm{VL}(4)$ & $\mathrm{M}(2)$ & $\mathrm{H}(1)$ \\
\hline & Sediment deposition problem & $\mathrm{H}(1)$ & $M(2)$ & $\mathrm{L}(3)$ & $\mathrm{H}(1)$ & $\mathrm{M}(2)$ & $\mathrm{L}(3)$ \\
\hline \multirow[t]{4}{*}{ Social } & Land acquisition problem & $\mathrm{H}(1)$ & $M(2)$ & $\mathrm{L}(3)$ & $\mathrm{M}(2)$ & $\mathrm{L}(3)$ & $\mathrm{L}(3)$ \\
\hline & Necessity of legal action & $\mathrm{H}(1)$ & VL(4) & VL(4) & $\mathrm{H}(1)$ & $\mathrm{VL}(4)$ & VL(4) \\
\hline & $\begin{array}{l}\text { Opportunity for vehicle movement and infrastructure } \\
\text { development }\end{array}$ & VL(1) & VL(1) & $\mathrm{H}(4)$ & VL(1) & VL(1) & $\mathrm{H}(4)$ \\
\hline & Opportunity to improve aesthetic & $\mathrm{H}(4)$ & $\mathrm{VL}(1)$ & $\mathrm{VL}(1)$ & $\mathrm{H}(4)$ & $\mathrm{VL}(1)$ & $\mathrm{VL}(1)$ \\
\hline
\end{tabular}

I = natural channel with sodding slope, $\mathrm{II}=$ natural channel with lined slope and III = box culvert

$\mathrm{H}=$ high, $\mathrm{M}=$ medium, $\mathrm{L}=$ low and $\mathrm{VL}=$ very low

${ }^{*}$ Lakh $=0.1$ Million 
Table 2: Standardized and total score of alternatives

\begin{tabular}{|c|c|c|c|c|c|c|c|c|}
\hline & & & \multicolumn{3}{|c|}{ Choukidekhi - Kanishail } & \multicolumn{3}{|c|}{ Kanishail - Topoban } \\
\hline & \multirow[b]{2}{*}{ Criteria } & \multirow[b]{2}{*}{ Weight } & \multicolumn{6}{|c|}{ Alternatives } \\
\hline & & & I & II & III & I & II & III \\
\hline Technical & Risk of design failure & 1 & 1 & 0.666 & 0 & 1 & 0.666 & 0 \\
\hline \multirow{2}{*}{ Economic } & Construction cost (Lakh ${ }^{*}$ Tk./km) & 1.5 & 1 & 0.467 & 0 & 1 & 0.596 & 0 \\
\hline & Maintenance cost (Tk./km/y) & 1.5 & 1 & 0 & 0 & 1 & 0 & 0 \\
\hline \multirow[t]{2}{*}{ Environment } & Water quality deterioration & 1 & 1 & 0.333 & 0 & 1 & 0.333 & 0 \\
\hline & Sediment deposition problem & 1 & 0 & 0.5 & 1 & 0 & 0.5 & 1 \\
\hline \multirow[t]{4}{*}{ Social } & Land acquisition problem & 1.5 & 0 & 0.5 & 1 & 0 & 1 & 1 \\
\hline & Necessity of legal action & 1.5 & 0 & 1 & 1 & 0 & 1 & 1 \\
\hline & $\begin{array}{l}\text { Opportunity for vehicle movement and infrastructure } \\
\text { development }\end{array}$ & 1.5 & 0 & 0 & 1 & 0 & 0 & 1 \\
\hline & Opportunity to improve aesthetic & 1.5 & 1 & 0 & 0 & 1 & 0 & 0 \\
\hline \multicolumn{2}{|c|}{ Total Value/Score } & & 6.5 & 4.78 & 5.5 & 7 & 5.73 & 5.5 \\
\hline
\end{tabular}
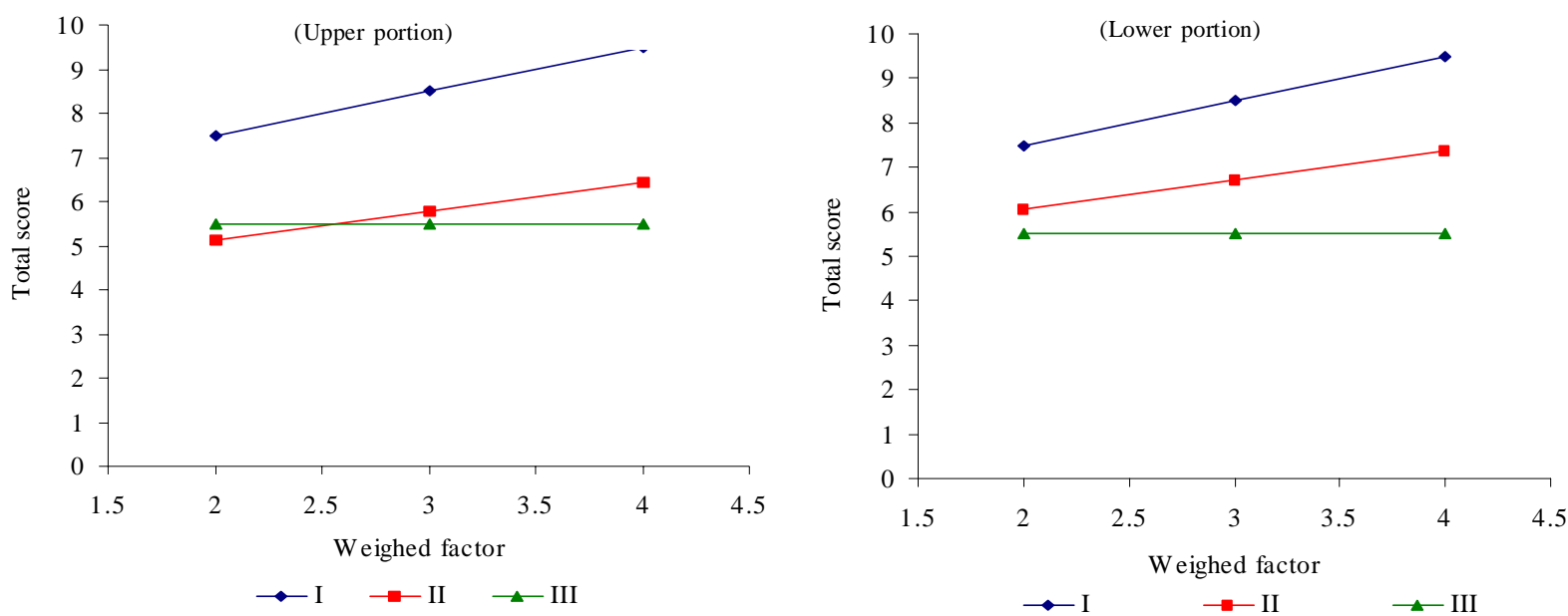

Fig. 3a: Effect of technical criteria (other remain same) on choice of best alternatives
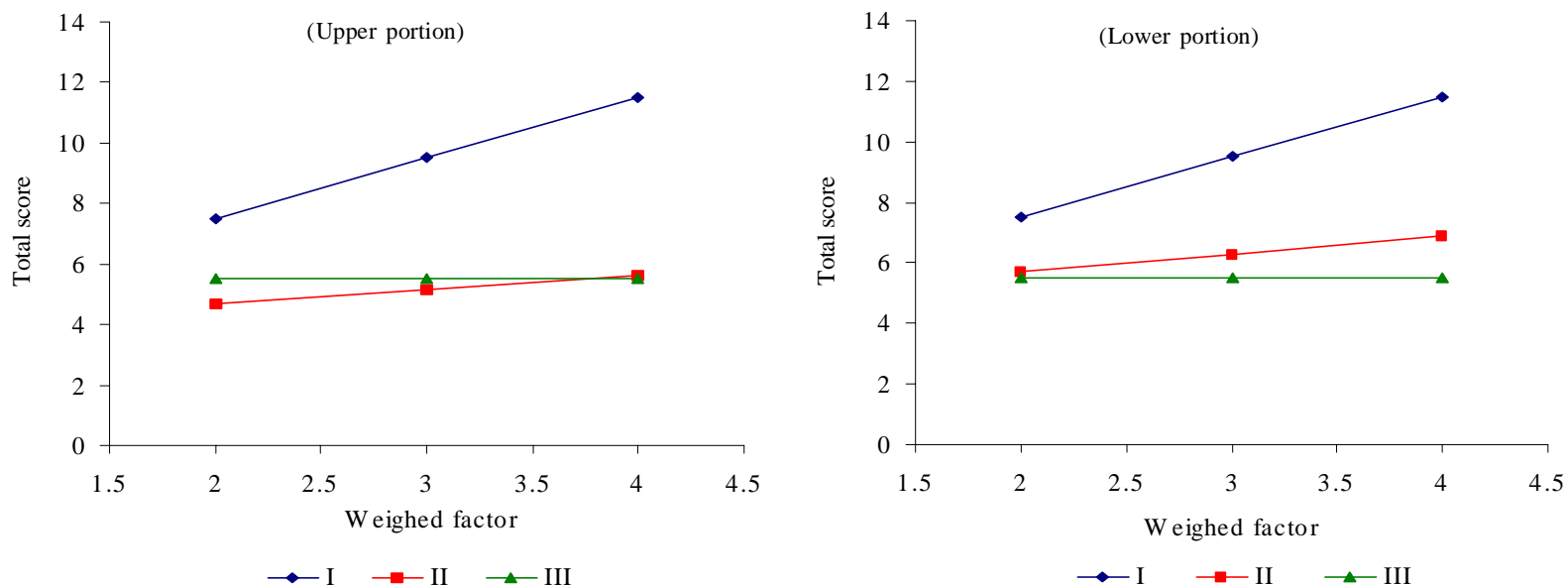

Fig. 3b: Effect of economic criteria (other remain same) on choice of best alternatives 
Int. J. Environ. Sci. Tech., 5 (2), 195-204, Spring 2008
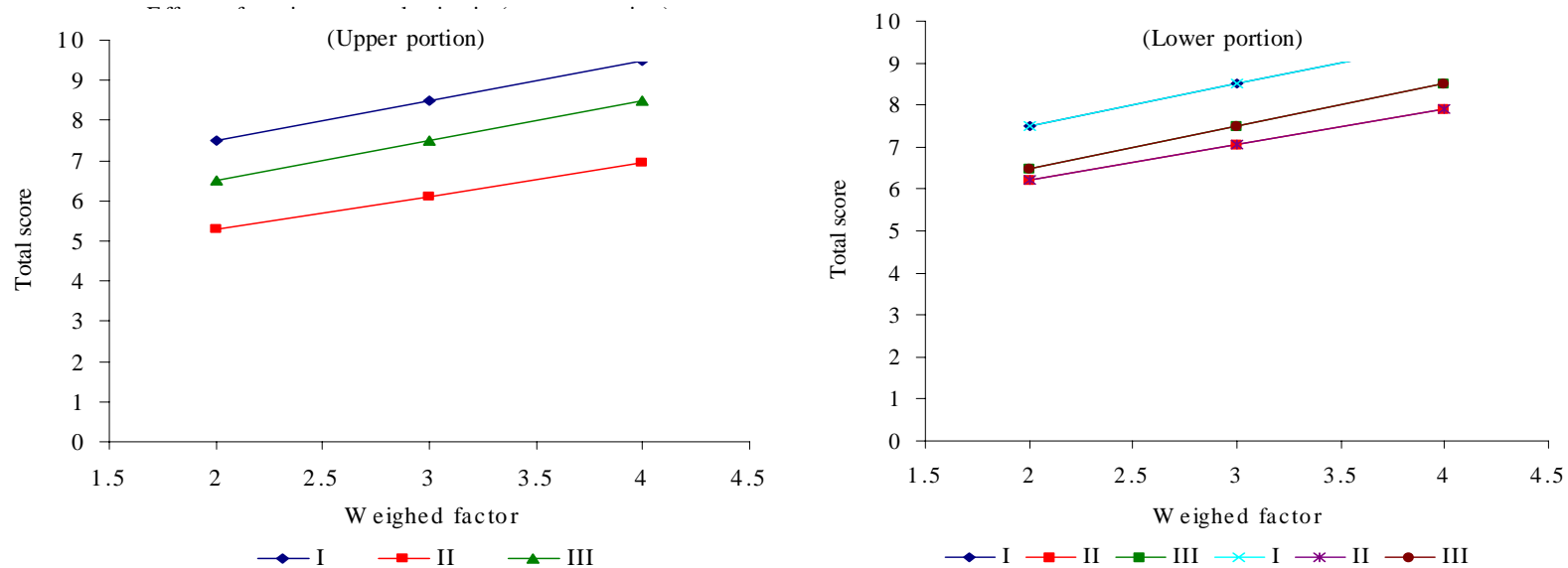

Fig. 3c: Effect of environment criteria (other remain same) on choice of best alternatives
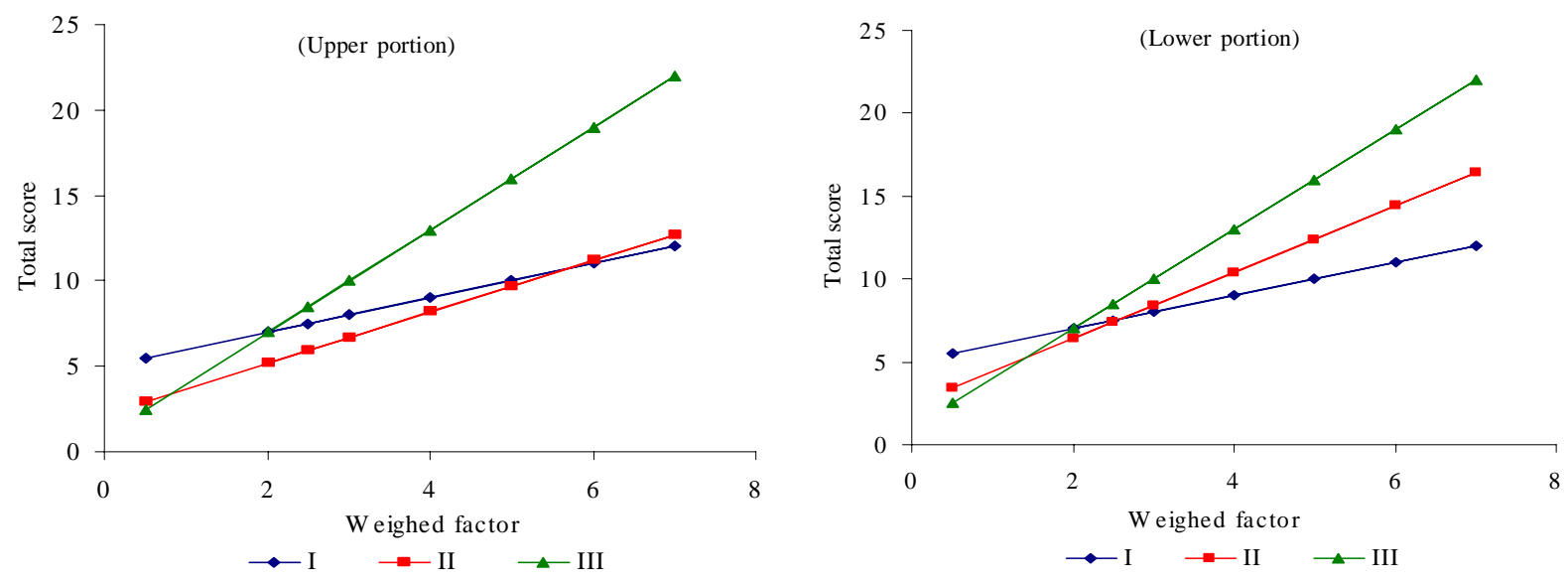

Fig. 3d: Effect of social criteria (other remain same) on choice of best alternatives
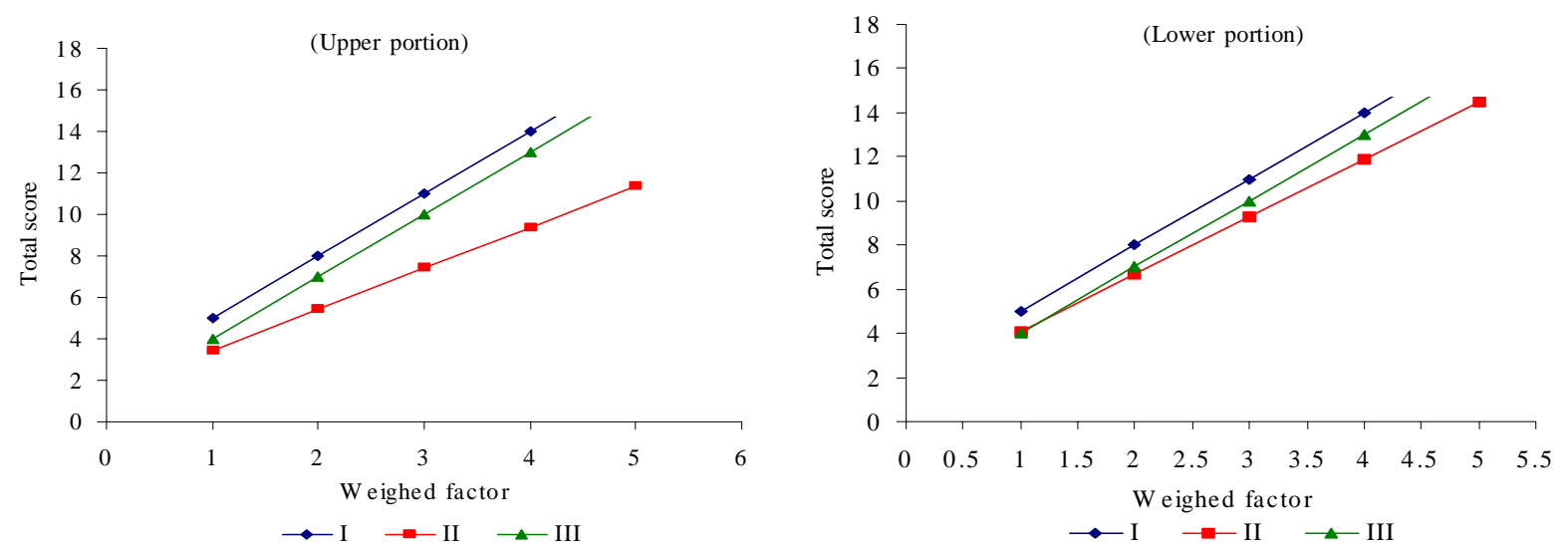

Fig. 3e: Effect of both economic and social criteria (other remain same) on choice of best alternatives 

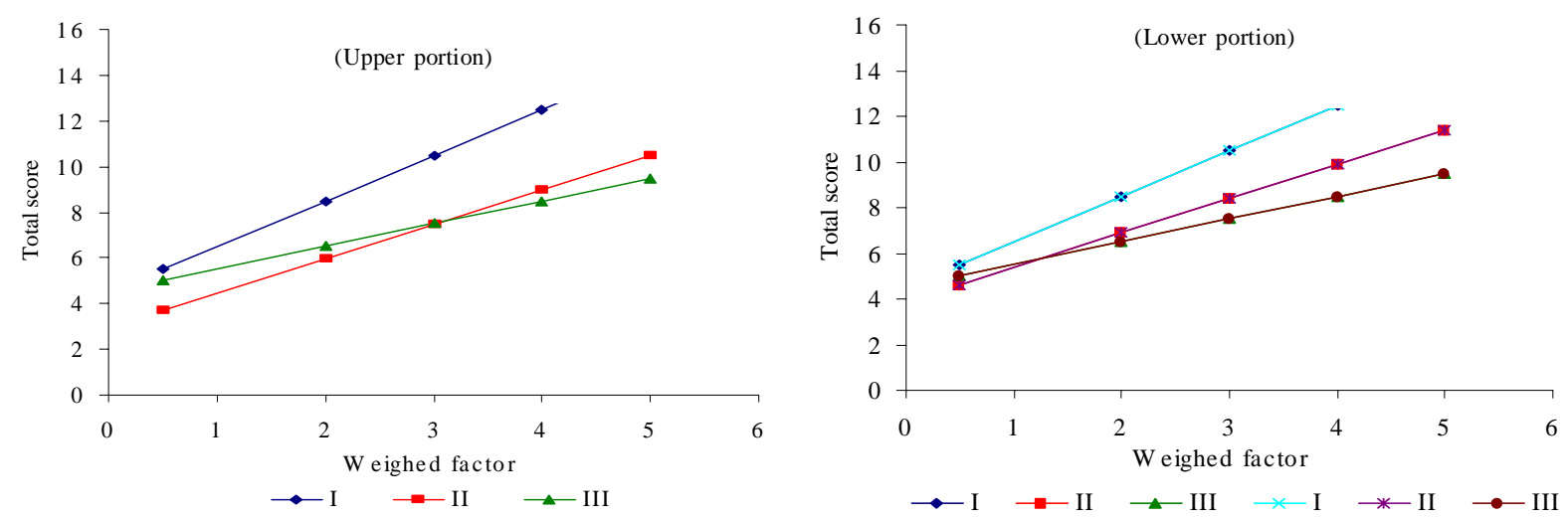

Fig. 3f: Effect of both technical and environment criteria (other remain same) on choice of best alternatives I = Alternative sodding natural channel; II = Alternative lined natural channel; III = Alternative box culvert;

Upper portion = Malnichara channel from Choukidekhi to Kanishail; Lower portion = Malnichara channel from Kanishail to Topoban

Although respondents were very confident to give high score for box culvert in case of vehicle movement and infrastructure development, they provided reverse scores in order to improve aesthetic/recreational facilities. Since all scores are not expressed in the same unit, standardization is necessary. Economic and social criteria were assigned weighed factor of 1.5. After weighed sum, the total value/ scores of sodding natural channel, lined natural channel and box culvert were found 6, 4.78 and 5.5, respectively for the upper portion of the channel whereas for the lower portion values were 6.5, 5.73 and 5.5, respectively. For both portions, sodding natural channel was found to be the best alternative. Box culvert is preferable rather than lined channel in the upper portions but in the lower portion the case is vice versa. The standardized scores and total scores are shown in the Table 2. In the planning process, a number of uncertainties and assumptions have to be made. The scenario variables are beyond the control of the planner and decision maker. In the MCDA, choices are made on the basis of evaluation method, the standardization technique and the weighed factor given to the selected criteria. Therefore, attempt was taken to perform sensitivity analysis. In the present study, technical and environmental criteria were assigned weighed coefficient of 1 whereas economic and social criteria were assigned weighed coefficient of 1.5 on the basis of subjective evaluations by respondents and experts. Sensitivity analysis was performed by changing weight coefficient of all criteria. When one's weighed coefficient changes, other's weighed coefficient remains constant. Impacts of sensitivity analysis on the choice of the best alternatives are given in Fig. 3 (a-f). It is very clear that technical, economic and environmental criteria has no effect on the best alternative (I, sodding natural channel) on both portions of the channel and a very little effect on the value of alternatives II (lined natural channel) and III (box culvert). Furthermore, social criteria have significant effect on the choice of alternatives. Beyond weightage factor 2 , the best alternative is box culvert instead of sodding natural channel on both portions of the channel. However, there are no effect of concurrent technical-environmental criteria and economic-social criteria on the best alternative of sodding natural channel on both upper and lower portions of the channel.

Natural channels have a very significant role in the hydrologic systems of any city or region. Any improvement of natural channels must be properly planned. The Malnichara is one of the major channels in Sylhet. In this study, three alternatives of its improvement have been evaluated by the MCDA method. Hydrologically, the channel is divided into two portions: upper portion (Choukidekhi-Kanishail) and lower portion (Kanishail-Topoban). Both parts were analyzed separately. Nine criteria were selected from four groups of technical, economic, environment and social aspects. Technical and environmental criteria were assigned a weighed coefficient of 1 whereas economic and social criteria were assigned a weighed coefficient of 1.5. The interviews with stakeholders and consultation with experts were carried out throughout the study period from the selection of criteria to assignment of weighed coefficients and 
scores to alternatives. For both portions of the channel, sodding natural channel was found to be the best alternative. Sensitivity analysis showed that only social criteria have a significant effect on choosing the best alternative. Beyond the weighed coefficient 2, box culvert is found to be the best alternative instead of sodding natural channel.

\section{REFERENCES}

Allett, E. J., (1986). Environmental impact assessment and decision analysis. J. Oper. Res. Soc., 37 (9), 901-910.

Arvai, J.; Gregory, R. (2003). Testing alternative decision approaches for identifying cleanup oriorities at contaminated sites. Environ. Sci. Tech., 37 (8), 14691476

Bella, A.; Duckstein, L.; Szidarovszky, F., (1996). A multicriterion analysis of the water allocation conflict in the upper rio Grande river basin. Appl. Math. Com., 77 (2-3), 245-265.

Belton, V.; Stewart, T. J., (2002). Multiple criteria decision analysis-An integrated approach. Kluwer Academic Publishers: Boston, Dordrecht, London.

Brown, C. A., (1984). The central Arizona water control study: A case for multiobjective planning and public involvement. Water Resour. Bull., 20 (3), 331-337.

Cai, X.; Lasdon, L.; Michelsen, A. M., (2004). Group decisionmaking in water resources planning using multiple objective analysis. J. Water Res. Pl-ASCE , 130 (1), 4-14.

Chowdhury, R. K., (2005). Planning for integrated storm water drainage management of the lower part of Malnichara in Sylhet city. M.Sc. (Water Resources Development) thesis, Bangladesh University of Engineering and Technology, Dhaka-1000, Bangladesh.

Clemen, R. T., (1996). Making hard decision: An introduction to decision analysis. Duxbury Press, Wadsworth Publishing Company, New York.

Dodgson, J., Spackman, M.; Pearman, A.; Phillips, L. (2000). Multi-Criteria analysis: A aanual. London: Department of the Environment, Transport and the Regions. Available at http://www.odpm.gov.uk/about/multicriteria/index.htm.

Ganoulis, J., (2003). Evaluating alternative strategies for wastewater recycling and reuse in the mediterranean area. Water Sci. Tech.: Water Supply., 3 (4), 11-19.

Gregory, R.; Keeney, R., (1994). Creating policy alternatives with stakeholder values. Manage. Sci., 40 (8), 1035-1048.

Herath, G., (2004). Incorporating community objectives in improved wetland management: The use of the analytic hierarchy process. J. Environ. Manage., 70 (3), 263-273.

Herwijnen, M.; Rietveld, P.; Thevenet, K.; Tol, R., (1995). Sensitivity analysis with interdependent criteria for multicriteria decision making: The case of soil pollution treatment. J. MultiCri. Dec. Anal., 4 (1), 57-70.
Hobbs, B. F.; Meier, P., (2000). Energy decisions and the environment: A guide to the use of multicriteria methods. Kluwer Academic Publishers, Boston, Dordrecht, London, 257.

Hostmann, M.; Borsuk, M.; Reichert, P.; Truffer, B., (2005). Stakeholder values in decision support for river rehabilitation. Large rivers. 15 (1-4), 491-505.

Ko, S. K.; Fontane, D. G.; Margeta, J., (1994). Multiple reservoir system operational planning using multicriteria decision analysis. Eur J. Oper. Res., 76, 428-439.

Lahdelma, R.; Salminen, P.; Hokkanen, J., (2000). Using multicriteria methods in environmental planning and management. Environ. Manage., 26 (6), 595-605.

Marttunen, M.; Hämäläinen, R. P., (1995). Decision analysis interviews in environmental impact assessment. Eur. J. Oper. Res., 87 (3), 551-563.

Marttunen, M.; Suomalainen, M., (2005). Participatory and multi objective development of water course regulationcreation of regulation alternatives from stakeholders' preferences. J. MultiCri. Dec. Anal., 13 (1), 29-49.

Ning, S. K.; Chang, N., (2002). Multi-objective, Decisionbased assessment of a water quality monitoring network in a river system. J. Environ. Monitor., 4 (1), 121-126.

Rajabi, S.; Hipel, K. W.; Kilgour, D. M., (2001). Multiple criteria screening of a large water policy subset selection problem. J. Am. Water Resour. As., 37 (3), 533-546.

Raju, K. S.; Duckstein, L.; Arondel, C., (2000). Multicriterion analysis for sustainable water resources planning: A case study in Spain. Water Resour. Manage., 14 (6), 435-456.

Ridgley, M. A.; Rijsberman F. R., (1992). Multicriteria evaluation in a policy analysis of a rhine estuary. Water Resour. Bull., 28 (6), 1095-1110.

Roy, B., (1996). Multicriteria methodology for decision aiding. Kluwer Academic Publishers, Boston, Dordrecht, London.

SCC (2005). Overview of Sylhet city. Bulletin of the Sylhet City Corporation (SCC), Sylhet, Bangladesh.

Senecah, S., (2004). The trinity of voice: The role of Practical theory in planning and evaluating the effectiveness of environmental participatory processes. In communication and public participation in environmental decision making, Depoe, S. P., Delicath, J. W., Elsenbeer, M. F. A. (Eds). State University of New York Press, 13-34.

Stewart, T. J.; Scott, L., (1995). A scenario-based framework for multicriteria decision analysis in water resources planning. Water Resour. Res., 31(11), 2835-2843.

Weber, M.; Borcherding, K., (1993). Behavioral influences on weight judgements in multiattribute decision making. Eur. J. Oper. Res., 67 (1), 1-12. 


\section{AUTHOR (S) BIOSKETCHES}

Chowdhury, R. K., South Australia Center for Water Management and Reuse, School of Natural and Built Environments, University of South Australia, Mawson Lakes, SA 5095, Australia.

Email: rezaul.chowdhury@unisa.edu.au

Rahman, R., Institute of Water and Flood Management, Bangladesh University of Engineering and Technology, Dhaka-1000, Bangladesh. Email: rezaur@iwfm.buet.ac.bd

This article should be referenced as follows:

Chowdhury, R. K; Rahman, R., (2008). Multicriteria decision analysis in water resources management: the malnichara channel improvement. Int. J. Environ. Sci. Tech., 5 (2), 195-204. 